IRA-International Journal of Applied Sciences ISSN 2455-4499; Vol.07, Issue 01 (2017)

Institute of Research Advances

Pg. no. 1-5

https://research-advances.org/index.php/IRAJAS

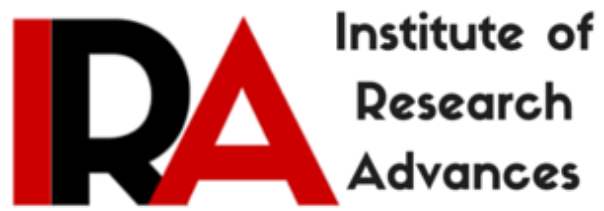

\title{
Water Quality Variation while Transporting Hypselobarbus Kurali Anesthetized with 2- Phenoxy Ethanol
}

\author{
Sherly Williams $\mathbf{E}^{\#}$ \\ Environmental Sciences, Aquaculture and Fish Biotechnology Lab, P G and Research \\ Department of Zoology, Fatima Mata National College, Kollam, Kerala, India:
}

\footnotetext{
\#Corresponding author.

Type of Review: Peer Reviewed.

DOI: http://dx.doi.org/10.21013/jas.v7.n1.p1
}

Williams E, S. (2017). Water Quality Variation while Transporting Hypselobarbus Kurali Anesthetized with 2- Phenoxy Ethanol. IRA-International Journal of Applied Sciences (ISSN 2455-4499), 7(1), 1-5. doi:http://dx.doi.org/10.21013/jas.v7.n1.p1

(C) Institute of Research Advances

(c) EY-NC

This work is licensed under a Creative Commons Attribution-Non Commercial 4.0 International License subject to proper citation to the publication source of the work.

Disclaimer: The scholarly papers as reviewed and published by the Institute of Research Advances (IRA) are the views and opinions of their respective authors and are not the views or opinions of the IRA. The IRA disclaims of any harm or loss caused due to the published content to any party. 


\section{ABSTRACT}

Transportation of fishes from study site to the laboratory needs lot of care as the fish is very sensitive to even minor changes in the surroundings. The prime response from the fishes was random running and hitting its head and body against the medium in which it is transported. Secondly it was found excreting a lot of ammonia waste which will degrade the water quality and there by lead to poor survival chances. Anesthetized transportation thus forms a boon in aquaculture. The fish meant for transportation is anesthetized hence it will not run and also will not eliminate wastes. A solution of $1 \mathrm{ml}$ of 2-Phenoxy ethanol in $5 l$ of water was prepared and used for the transportation trials which were conducted in heavy duty poly bags. The average weight of brood fish was $200 \mathrm{~g}$. Five numbers of brood fishes were accommodated in a bag for the transportation for 2 hours. Water quality parameters like temperature, $\mathrm{pH}$, dissolved oxygen, ammonia and alkalinity were assessed following standard methods using water quantity analyzing probe (Eutech, S-660). The studies were carried out repeatedly four times during transportation so as to confirm results. The results have shown that as time proceeds the water quality of control changed drastically whereas the experiment retained the change in water quality towards a standard range throughout the transportation trial. As the fishes are anesthetized the biological activities will slow down which result in lesser consumption of oxygen, low excretory waste and so on. So anesthetizing H.kurali with 2- phenoxy ethanol is advisable.

Key words: Anesthesia, Hypselobarbus kurali, transportation, 2- phenoxyethanol, aquaculture.

\section{Introduction}

Transportation of fishes from study site to the laboratory needs lot of care as the fish is very sensitive to even minor changes in the surroundings. The prime response from the fishes was random running and hitting its head and body against the medium in which it is transported. Secondly it was found excreting a lot of ammonia waste which will degrade the water quality and there by lead to poor survival chances. Anesthetized transportation thus forms a boon in aquaculture. The fish meant for transportation is anesthetized hence it will not run and also will not eliminate wastes.

2-PE (2-Phenoxyethanol)[1-hydroxy -2-phenoxyethane] is a colourless, oily, aromatic liquid with a burning taste and has a solubility in water of $27 \mathrm{~g} / \mathrm{l}$. at $20^{\circ} \mathrm{C}$ (Merk and company, 1989). It is used as a topical anesthetic. It is a mild toxin and may cause some irritation to the skin, therefore any contact with the eyes should be avoided (Bell, 1987). Based on human toxicology data, it may also cause liver and kidney damage (Summerfelt and Smith, 1990).Anesthetic trials were performed. Four levels of anesthetics were evaluated which includes $300 \mu l / l, 400 \mu l / l, 500 \mu l / l$ and $600 \mu l / l$ with four repeats. Healthy fishes from the wild caught group were selected for transportation. Each level of anesthetics were measured out into a $50 \mathrm{ml}$ reagent bottle, mixed with $30 \mathrm{ml}$ of water and stirred to disperse the chemical before adding to the anesthesia inducing tub. Observation on 10 fishes were made at each level. The stages of anesthetization were differentiated as induction, maintenance and recovery (Sajan et al, 2012). The efficiency of the anesthetics were assessed by considering three stages of induction $\left(\mathrm{I}^{1}, \mathrm{I}^{2}, \mathrm{I}^{3}\right)$ and three stages of recovery $\left(\mathrm{R}^{1}, \mathrm{R}^{2}, \mathrm{R}^{3}\right)$ in Hypselobarbus Kurali. An induction time of $180 \mathrm{sec}$ or less and complete recovery with in $300 \mathrm{sec}$ suggested by Marking and Meyer 1985 and Trzebiaoto wski, 1996 was employed to assess the induction and recovery stage in the Hypselobarbus Kurali. Dosages of anesthesia adopted for various teleosts (Weber et al, 2009) were adopted as the base information. Both treatment and recovery 
water were taken from the natural ecosystem itself, where the fishes lived. When the fishes reached the stage three of aesthesia $\left(\mathrm{I}^{3}\right)$, it was immediately transferred to the recovery tub for recording the recovery stage $\left(\mathrm{R}^{1}, \mathrm{R}^{2}\right.$ and $\left.\mathrm{R}^{3}\right)$. The induction and recovery instance for each concentration was measured by using an electronic stop watch. Experiments were repeated four times to verify the findings. The recovered fishes were transferred to the observation tanks $(100 \mathrm{l})$ and held for 7 days, to assess the post recovery mortality (Pawar et al, 2011)

\section{Methodology}

A solution of $1 \mathrm{ml}$ of 2- Phenoxy ethanol in $5 \mathrm{l}$ of water was prepared and used for the transportation trials which were conducted in heavy duty poly bags. The average weight of brood fish was $200 \mathrm{~g}$. Five numbers of brood fishes were accommodated in a bag for the transportation for 2 hours. Water quality parameters like temperature, $\mathrm{pH}$, dissolved oxygen, ammonia and alkalinity were assessed following standard methods using water quantity analyzing probe (Eutech, S-660). The studies were carried out repeatedly four times during transportation so as to confirm results

\section{Result and Discussion}

To understand the water quality variation with respect to variation in time and the influence of anesthetics on water quality maintenance, group statistics and independent sample test were performed. Control was set in which no anesthetic agents were added and experiment was set with anesthetizing agents added into it. Water quality parameters like temperature, $\mathrm{pH}$, dissolved oxygen, ammonia and alkalinity were assessed. The dissolved oxygen (Fig.1) level for first time boundary (30 mnts) was $4.54 \mathrm{mg} / \mathrm{l}$ for control and $4.52 \mathrm{mg} / \mathrm{l}$ for experiment. At $60 \mathrm{mnts}$ the dissolved oxygen level varied and it was $3.53 \mathrm{mg} / \mathrm{l}$ for control and $3.72 \mathrm{mg} / \mathrm{l}$ for experiment. For $90 \mathrm{mnts}$ observation it was found that dissolved oxygen level was $2.61 \mathrm{mg} / \mathrm{l}$ for control and $3.59 \mathrm{mg} / \mathrm{l}$ for experiment. For $120 \mathrm{mnts}$ observation the oxygen level was 2.15 $\mathrm{mg} / \mathrm{l}$ for control and $3.62 \mathrm{mg} / \mathrm{l}$ for experiment. Thus from the trend of the values analyzed it was observed that the control showed decreased value in dissolved oxygen concentration drastically when compared to that of experiment which exhibits a slow variation, that also in a mild range. As the fishes in the experiment were anesthetized their physical and biological activities got slowed down and so they used less amount of oxygen compared to the control. $\mathrm{pH}$ (Fig.2) is one among the important water quality parameter which governs several other water quality parameters. The values observed for $30 \mathrm{mnts}, 60 \mathrm{mnts}, 90 \mathrm{mnts}$ and 120 mnts time scale were 7.07, 8.68, 8.70 and 8.72 for control and 7, 7.21, 7.57 and 7.70 for experiment respectively. As the fishes in the experiment set up were anesthetized the rate of elimination of excretory wastes was negligibly low and thus the rate of change of $\mathrm{pH}$ was also low. Alkalinity (Fig.3) was measured for each concentrations of the anesthetic 2-phenoxy ethanol and it was observed that for 30 mnts the alkalinity was $85.50 \mathrm{ppt}$ for control and $85.75 \mathrm{ppt}$ for experiment set up. In the case of $60 \mathrm{mnts}$ time scale the alkalinity was fluctuating around $93.00 \mathrm{ppt}$ for control and $86.50 \mathrm{ppt}$ for experiment. For $90 \mathrm{mnts}$ the alkalinity was $99.25 \mathrm{ppt}$ for control and $87.25 \mathrm{ppt}$ for experiment. At a concentration of $120 \mathrm{mnts}$ the alkalinity was $108.50 \mathrm{ppt}$ and $89 \mathrm{ppt}$ respectively. Here also the excretory waste reduction in the transportation system due to anesthesia may be the reason for reduction in the increase of alkalinity. For all the four time scales viz 30 mnts, 60 mnts, 90 mnts and 120 mnts, the temperature (Fig.4) for control was $24.48^{\circ} \mathrm{C}, 26.20^{\circ} \mathrm{C}, 28.65^{\circ} \mathrm{C}$, and $28.66^{\circ} \mathrm{C}$ respectively. For experiment it was $23.28^{\circ} \mathrm{C}, 24.45^{\circ} \mathrm{C}, 25.12^{\circ} \mathrm{C}$, and $25.34^{\circ} \mathrm{C}$. For both control and experiment there was no need for the increase in temperature as the fish was transported in air conditioned atmosphere. But due to the rash movement of fishes within the control set up the temperature rise might have happened. The ammonia concentration (Fig.5) in the experiment and 
control bags for the present study is as follows. For control it was $0.05 \mathrm{ppt}$ at $30 \mathrm{mnts}$ and $0.04 \mathrm{ppt}$ for experiment at same time scale. For $60 \mathrm{mnts}$ the ammonia level was $0.07 \mathrm{ppt}$ for control and $0.04 \mathrm{ppt}$ for experiment. Control had $0.098 \mathrm{ppt}$ and $0.05 \mathrm{ppt}$ for experiment at $90 \mathrm{mnts}$. At $120 \mathrm{mnts}$ the control and experiment had an ammonia range of 0.12 ppt and 0.06 ppt respectively. As the fish excretes its nitrogenous waste in the form of ammonia, the water surrounding it will have a hike in ammonia concentration and here the control had high concentration compared to experiment as in experiment anesthetized fish had released only negligible amount of waste. The water quality parameters observed in the experiment were temperature, $\mathrm{pH}$, dissolved oxygen, alkalinity and ammonia which are comparable with the observations of Sajan et al. (2012).

\section{Conclusion}

Anesthetizing fishes for easy transportation is becoming a common practice these days. The appropriate use of these anesthetic will definitely be of great help in facilitating easy handling, propagation and stock revival of this endangered indigenous fish. Once the fish is anesthetized, the rate of physical stress for the fish could be reduced which ultimately provide better results. As the fishes are anesthetized the biological activities will slow down which result in lesser consumption of oxygen, low excretory waste and so on. So anesthetizing H.kurali with 2- phenoxy ethanol is advisable.

\section{References}

Bell G., 1987. An outline of anesthetic and anesthesia for salmonids, a guide for fish culturists in British Columbia 16pp. Canadian Technical Report of Fisheries Aquatic Sciences No. 1534.

Merck \& Company (1996). The Merck index, 12th ed. Rahway, NJ, U.S.A.

Pawar, H.B., S.V. Sanaye, R.A. Sreepada, V. Harish, U. Suryavanshi, Tanu and Z.A. Ansari. 2011. Comparison of efficacy of four anaesthetic agents in the yellow seahorse, Hippocampus kuda (Bleeker, 1852). Aquaculture 311:155-161.

Sajan, S., T.V.A. Mercy and V. Malika. 2012. Use of an eco-friendly anaesthetic in the handling of Puntius denisonii (Day, 1865) - an endemic ornamental barb of the Western Ghats of India. Indian Journal of Fisheries 59:131-135.

Summerfelt, R. C. and L. S. Smith., 1990. Anesthesia, surgery, and related techniques. In Methods for fish biology. R. C. Schreck and P. B. Moyle, eds. Am. Fish. Soc., Bethesda, MD, U.S.A., pp. 213-272.

Weber, R.A., J.B. Peleteiro, L.O.García-Martín and M. Aldegunde. 2009. The efficacy of 2phenoxyethanol, metomidate, clove oil and MS-222 as anaesthetic agents in the Senegalese sole (Solea senegalensis Kaup, 1858). Aquaculture 288:147-150. 


\section{Supplementary Section: Figures}

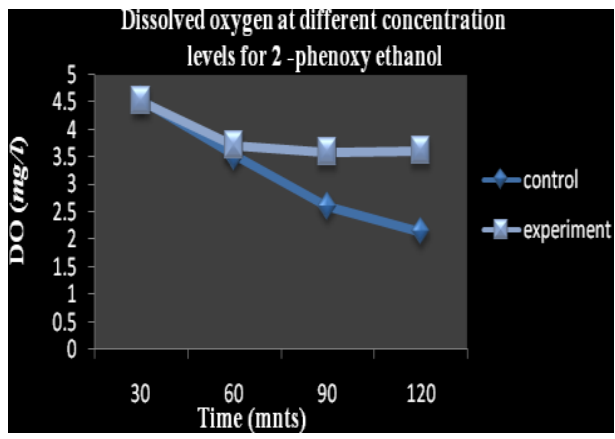

Fig.1

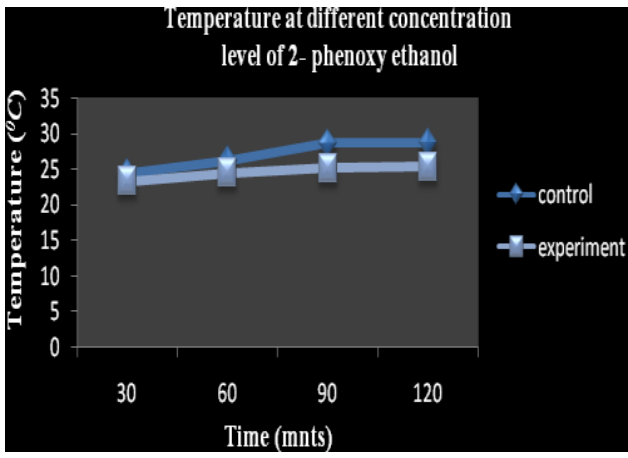

Fig.3

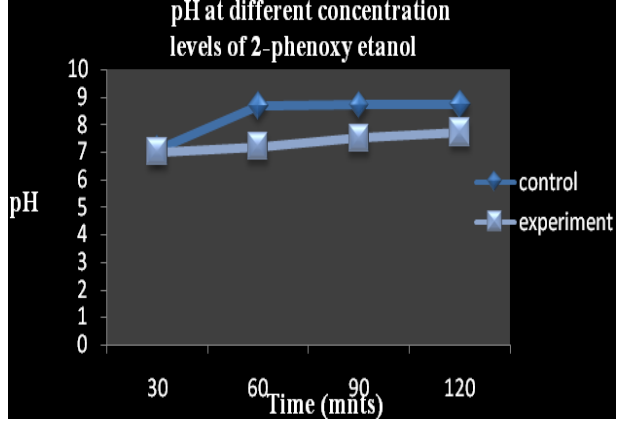

Fig.2

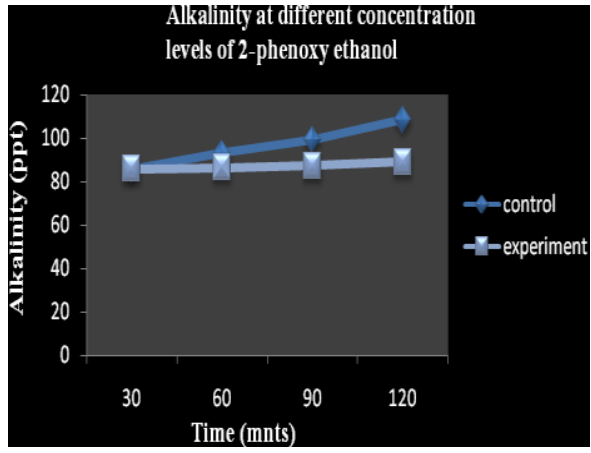

Fig.4

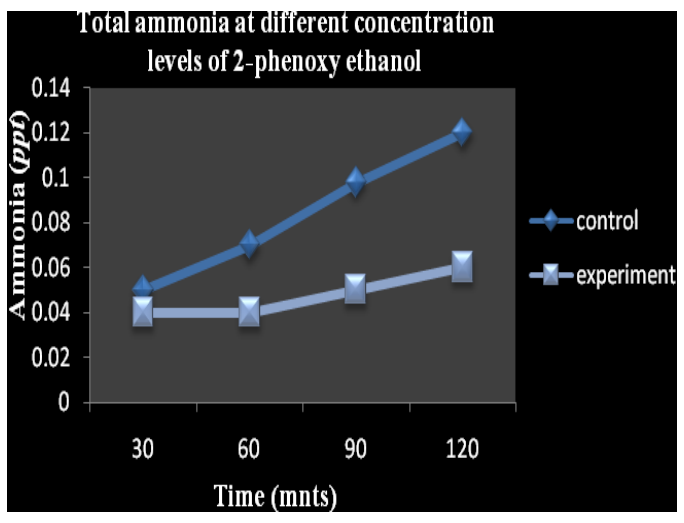

Fig.5 